\title{
Repensando o papel da China nas Operações de Paz das Nações Unidas: respondendo aos desafios a partir do Sul Global?
}

\author{
Rethinking China's role in the United Nations Peace Operations: responding to the challenges from the \\ Global South?
}

DOI: https://doi.org/10.22456/2178-8839.112326

Talita de Mello Pinotti Universidade Estadual de Campinas (UNICAMP) e Faculdades de Campinas (FACAMP), Campinas, Brasil talitapinotti@yahoo.com.br

Patricia Capelini Borelli PPGRI San Tiago Dantas (Unicamp, Unesp. PUC-SP), com bolsa CAPES, e Faculdades de Campinas (FACAMP), Campinas, Brasil borelli.pc@gmail.com

\section{Resumo}

Diante dos 50 anos da entrada da República Popular da China na Organização das Nações Unidas (ONU), o artigo tem como objetivo explorar a mudança do posicionamento do país no Conselho de Segurança, considerando a crescente participação chinesa em operações de paz. A partir de uma revisão bibliográfica, são apresentadas as principais características das operações de paz e os principais desafios enfrentados pelo Conselho na utilização desse instrumento. Em seguida, é estudada a progressiva mudança do engajamento da China nas missões. A literatura trata de três fases: abstenção (1971-1981); aproximação e flexibilização (1982-1998); e gradativa cooperação (2001-2010). Propomos uma quarta fase, denominada engajamento ativo (2010-2020), na qual o país se destaca como o segundo maior contribuinte financeiro, além de entrar para a lista dos dez maiores país es contribuintes de polícia e tropas para as missões. Os dados sobre tais contribuições foram coletados a partir dos relatórios oficiais da ONU e indicam a crescente relevância chinesa no financiamento e suporte das operações de paz, áreas essas que, desde os anos 1990, representam os principais desafios da ONU na área de segurança e defesa.
\end{abstract}

Palavras-chave: China; Organização das Nações Unidas; Operações de Paz;

\begin{abstract}
Considering the $50^{\text {th }}$ anniversary of the accession of the People's Republic of China to the United Nations (UN), this article aims at exploring the change in the country's position towards the Security Council, analyzing the increasing Chinese participation in Peace Operations. Starting with a literature review, we present the main characteristics of Peace Operations and the key challenges faced by the Council in applying such tool. Second, we introduce an analysis on the progressive change in China's engagement in these operations. Current discussions on the topic consider three phases: abstention (1971-1981); rapprochement and flexibilization (1982-1998); and increasing cooperation (2001-2010). We suggest a fourth phase, called active engagement (2010-2020) in which the country becomes a key player holding the position of second largest contributor to the budget of peace operation s and being among the top ten Troop and Police Contributing Countries. The data regarding contributions were collected from official UN reports and indicate the growing relevance of China to the funding and logistic support of peace operations, areas that since de 1990 s represent great challenges to the UN.
\end{abstract}

Keywords: China; United Nations; Peacekeeping Operations; 


\title{
Introdução
}

$\mathrm{Na}$ abertura da $70^{\mathrm{a}}$ sessão da Assembleia Geral (AG), em setembro de 2015, o presidente da China - Xi Jinping proferiu o seguinte discurso:

\begin{abstract}
Aproveito a oportunidade para anunciar a decisão da China em estabelecer um fundo para a paz e o desenvolvimento em apoio ao trabalho das Nações Unidas, disponibilizando US\$ 1 bilhão em um prazo de dez anos; em avançar na cooperação multilateral e promover a paz e o desenvolvimento. Também gostaria de anunciar que a China se juntará ao United Nations peacekeeping capabilities readiness system e, com isso, assumir a liderança na criação de uma força policial permanente para operações de paz e de uma tropa de prontidão para operações de paz de 8 mil soldados (UNITED NATIONS GENERAL ASSEMBLY, 2015b, p. 21, tradução nossa). ${ }^{1}$
\end{abstract}

O presidente chinês afirmou ainda que a segurança total dependia da estabilidadeinternacional e que, por isso, a China estava disposta a assumir o papel de "potência responsável”, seguir e manter as regras internacionais e otimizar o papel das estruturas de governança global.Em sua fala, Xi também atribuiu importância destacada às Nações Unidas, que teriam o grande objetivo de promover a cooperação internacional, por meio da redução das tensões, da promoção da paz e do desenvolvimento sustentável: compromissos assumidos pela República Popular da China (RPC) como membro da instituição.

O discurso de Xi Jinping marca uma mudança considerável do posicionamento inicial da RPC desde sua entrada na Organização das Nações Unidas $(\mathrm{ONU})^{2}$, há 50 anos. Sobretudo em relação às operações de paz ${ }^{3}$, sobre as quais a China tem demonstrado um olhar mais pragmático. Se nos anos 1970 a China desconfiava da neutralidade e da efetividade das operações, optando pelo distanciamento nas discussões, nos anos 2000 podemos observar maior interesse do país em cooperar e contribuir para as missões. A partir dos anos 2010, a RPC avança nesse sentindo, ao se declarar disposta a assumir os encargos de fornecer um bem público internacional, contribuindo com recursos financeiros e humanos. Em 2021, a RPC completa 50 anos de ONU com uma postura renovada de maior engajamento.

Tendo em mente a gradativa mudança no posicionamento da RPC, este artigo explora a transição do posicionamento chinês em relação às operações de paz da ONU dandoênfase às transformações mais recentes que, por sua vez, vão ao encontro dos principais desafios que a ONU enfrenta sobre as operações de paz: o financiamento e os recursos humanos. $\mathrm{O}$ artigo parte de uma revisãobibliográfica para apresentar as missões e a evolução desse instrumento, a fim de compreender os desafios enfrentados atualmente para a sua viabilização. Em seguida, observamos a mudança do posicionamento chinês a partir de três fases já presentes na literatura -de 1971 a 1981; de 1982 a 1998 ; de 2000 a 2010 -e propomos uma quarta fase, de 2010 até os dias atuais, marcada pelo engajamento ativo. Nessa etapa, analisamos documentos oficiais da ONU, como registros de reunião, relatórios de contribuições de pessoal para as operações de paz e resoluções sobre o orçamento desse instrumento. Destacamos especialmente as contribuições feitas pela China à organização. Por fim, refletimos sobre possíveis implicações do engajamento diferenciado da China, enquanto parte do Sul Global, frente aos atuais desafios do processo de formulação das operações de paz.

\footnotetext{
${ }^{1}$ Do original em inglês: I take this opportunity to announce China's decision to establish a 10-year, \$1 billion peace and development fund to support the work of the United Nations, advance multilateral cooperation and promote world peace and development. I also wish to announce that China will join the new United Nations peacekeeping capabilities readiness system and has therefore decided to take the lead in setting up a permanent formed peacekeeping police force and a standby peacekeeping force of 8,000 troops.

2 Importante lembrar que a RPC substituiu a República da China na ONU em 1971, o que justifica o recorte temporal escolhido neste artigo.

3 Por operações de paz, entendemos o conjunto de instrumentos disponíveis no âmbito das Nações Unidas que envolvem as operações de paz, tanto o aspecto tradicional como o aspecto multidimensional: prevenção de conflitos, peacemaking, peacekeeping, peacebulding e peace enforcement. $\mathrm{O}$ termo "missões" também será aqui utilizado como sinônimo de operações de paz.
} 


\section{O Conselho de Segurança das Nações Unidas e as Operações de Paz}

Na ONU, o Conselho de Segurança (CS) é o órgão responsável pela manutenção da paz e da segurança internacional, um dos pilares basilares da organização. O mandato do Conselhoé estabelecido pela Carta da ONU, no capítulo V, que estabelece que o CS deve ser composto por quinze Estados membros da ONU, sendo cinco deles permanentes: China, Estados Unidos, França, Reino Unido e Rússia, e dez membros rotativos, com mandatos de dois anos cada. O mesmo capítulo estabelece que os demais Estados Membros da ONU devem aceitar e acatar as decisões tomadas pelo Conselho (UNITED NATIONS, 2015).

Dentre as decisões que o Conselho precisa tomar, está a escolha de quais instrumentos serão utilizados para lidar com algum conflito específico ou possíveis ameaças à paz. Os instrumentos estão estabelecidos nos capítulos VI, VII e VIII da Carta da ONU e incluem desde a solução pacífica de disputas (capítuloVI), até ações mais rígidas, como a interrupção de relações econômicas ou mesmo o uso da força (capítulo VII). As decisões do CS são tomadas por meio de resoluções que, para serem adotadas, sãolevadas a voto pelos quinze membros, sendo necessários pelo menos nove votos afirmativos, sem votos contrários por parte dos cinco membros permanentes (também conhecidos como P -5). Como um dos P-5, a China desempenha um papel de extremarelevância, pois ovoto contrário do país pode significar a não adoção de uma resolução (UNITED NATIONS, 2015).

Embora não estejam prescritas na Carta da ONU, as operações de paz são um instrumento recorrentemente empregado pelo CS. O órgão é responsável por determinar a natureza, o mandato e a duração das operações, assim como seu monitoramento. A menção aos capítulos VI ou VII da Carta no mandato das missões ajuda a definir o escopo de cada operação (FAGANELLO, 2013, p. 84; UNITED NATIONS, 2020g). Originalmente, as operações de paz foram criadas para monitorar movimentos de cessar-fogo e o pós-conflito, garantindo um ambiente estável para as negociações de paz entre as partes, normalmente, dois Estados. Contudo, desde os anos 1990, as missões também são empregadas na prevenção de possíveis conflitos, não necessariamente entre Estados, e na facilitação do desenvolvimento pós -conflito (DIGOLIN, 2018; UZIEL, 2010).

Assim, alguns dos desafios recentes são: o estabelecimento de mandatos individualizados, desenhados para atender exclusivamente as necessidades de cada situação; a definição precisa de quando começa e, sobretudo, quando termina uma operação; e, como consequência desses fatores, como financiar as operações de paz, que têm se tornado altamente custosas devido a diversificação de suas atividades. Nesse cenário, o número de pessoas enviadas para as missões e os diferentes papéis demandados representa também uma grande dificuldade em termos de viabilização das operações. Além do envio de militares, o número de policiais e de profissionais civis de diferentes especializações cresceu significativamente. Ademais, o número de operações também aumentou desde o fim da Guerra Fria: se entre 1948 e 1989 foram empregadas 18 operações de paz da ONU, entre 1990-2013, esse número ultrapassou a casa dos 50 (UNITED NATIONS, 2020d).

O financiamento e o envio de pessoal são pontos centrais nas discussões sobre operações de paz. Apesar de ser o CS o responsável por determinar o mandato, o orçamento das missões é definido na AG, que conta com a participação de todos os Estados Membros da ONU. As contribuições para o orçamento das missões, contudo, são definidas de acordo com as capacidades de pagamento dos países, considerando o nível de desenvolvimento de cada um e sua participação no orçamento regular da ONU (UNITED NATIONS, 2020f).

Nesse caso, os Estados com menos condição de contribuir para o orçamento acabam por colaborar com o envio de tropas e/ou de polícia para atuar em campo. Os membros permanentes devem arcar com uma proporção maior do orçamento, devido ao papel diferenciado que desempenham na definição das operações, sobretudo os países desenvolvidos: Estados Unidos, França e Reino Unido, conhecidos como P -3 dentro do CS. Historicamente, China e Rússia têm menor contribuição orçamentária quando comparados aos P -3, lembrando que são considerados ainda como países em desenvolvimento. Essa divisão, porém, não se restringe ao campo orçamentário. 
SegundoWeiss e Kuele (2019), há uma “divisão do trabalho” específica na formulação das operações de paz que coloca os países desenvolvidos como responsáveis pelo financiamento de tais atividades, enquanto os países em desenvolvimento ${ }^{4}$ ficam responsáveis pelo envio de pessoal, principalmente de tropas e de polícia. ${ }^{5}$ Mais de $90 \%$ do pessoal que participa das operações são provenientes de três regiões: África, Ásia e América do Sul. Essa concentraçãoé justificada por motivos diferentes, considerando as perspectivas do Norte e do Sul Global. Enquanto o primeiro grupo alega que a contribuição de tropas teria como contrapartida, por exemplo, a ampliação do prestígio e do reconhecimento internacional, além de ganhos econômicos; o segundo grupo entende que, diante da obrigatoriedade de colaboração estabelecida pela Carta da ONU, o envio de tropas seria a principal opção, frente a alternativa de contribuição financeira.

Por sua vez, Malone e Thakur (2018) apontam que é comum que países ocidentais treinem e equipem os militares de países em desenvolvimento para participarem de operações, sobretudo as que escapam dos mandatos tradicionais de monitoramento, pois nelas os países ocidentais são menos propensos a contribuir com tropas. Tanto que é praticamente nula a participação de militares dos Estados Unidos e de outros países do Norte Global em missões africanas. Para os autores, a distribuição de tarefas resulta de uma relação desigual entre os países que têm maior capacidade de contribuição, mas que não estão dispostos a comprometer suas tropas em cenários arriscados, e os que têm menor capacidade acabam assumindo o fardo das missões mais expostas a riscos. Esse é um ponto interessante para analisar a participação chinesa, já que o país, sozinho, tem reduzido essa lacuna entre a contribuição financeira e a contribuição com tropas.

A situação fica ainda mais complexa quando consideramos a formulação dos mandatos das operações, que não só se concentra no CS, como atribui maior protagonismo aos P-3, penholders ${ }^{6}$ da maior parte das resoluções sobre operações de paz. Por isso, os países que contribuem com tropas (TCC) ou com polícia (PCC), em sua maioria do Sul Global, são marginalizados de boa parte do processo decisório, sendo chamados a opinar apenas nos estágios finais. O resultado são operações com mandatos cada vez mais amplos, mas com dificuldade de mobilizar os recursos humanos e financeiros necessários para sua implementação.

O descompasso entre o financiamento e a efetiva realização das missões é o principal desafio atual em relação às operações de paz. Com orçamentos, até pouco tempo, crescentes, há uma pressão constante sobre os Estados Membros para aumentarem suas contribuições, principalmente aqueles com maior capacidade de pagamento. Por exemplo, o orçamento do ano fiscal de 2020 foi de US\$ 6,6 bilhões, já registrando uma redução de cerca de 1,49\% em relação ao ano anterior (UNITED NATIONS, 2020). Dessa realidade decorrem duas principais consequências: (i) armadilha de cortes com o intuito de reduzir o orçamento a ser aprovado, os países, em especial os que mais contribuem, pressionam pelo corte de gastos nas missões sem considerar a complexidade de seus mandatos ou a situação em campo; (ii) problema de liquidez - muitos Estados, ou por não conseguirem cumprir com sua contribuição ou por usarem-nas como instrumento de barganha, atrasam seus pagamentos, o que inviabiliza a implementação dos gastos aprovados.

A partir desse cenário mais geral do CS e das operações de paz, podemos levantar possíveis implicações da emergência da China como um ator ativo nas missões. Desde sua entrada na ONU, em 1971, o posicionamento chinês sofreu transformações importantes, partindo de uma postura mais reservada sobre os motivos e as condutas das missões, para um papel mais assertivo, principalmente a partir de 2015. A transformação da postura da China é analisada na seção seguinte.

\footnotetext{
${ }^{4}$ Para os fins deste artigo, os termos "países em desenvolvimento" e "países do Sul Global” serão utilizados como aproximações, seguindo a sugestão de Weiss e Kuele (2019).

${ }^{5}$ Para ilustrar esse ponto, vale observar quais são os maiores países contribuintes com o envio de tropas para as missões em 2020 : Etiópia com 6.056 soldados, Bangladesh com 5.996 soldados, e Ruanda, com 5.208. Já em relação ao envio de polícia, os principais contribuintes são: Senegal com 1.207 policiais, Ruanda com 1.071, e o Egito, com 879 policiais (DEPARTMENT OF PEACE OPERATIONS, 2020).

${ }^{6} \mathrm{Na}$ linguagem do CS, penholders são os Estados responsáveis por elaborar a versão primária das resoluções.
} 


\section{As quatro fases da participação chinesa nas Operações de Manutenção da Paz}

A trajetória da RPC na instituição tem sido reflexo de seu desenvolvimento interno e da transformação de sua política externa diante de sua crescente projeção no sistema internacional. Ao analisar a participação da China na ONU, é interessante notar que o país fez um esforço gradativo de integração e de adequação às regras e normas internacionais. Nos seus 50 anos de participação, é possível observar uma China que partiu de uma postura contestadora em relação à organização, para uma China que hoje assume posições de liderança em temas centrais da agenda. Um dos melhores reflexos dessa transformação é sua postura em relação às operações de paz, que é geralmente dividida em três fases na literatura: a primeira, de abstenção (1971 a 1981); a segunda, de aproximação e flexibilização (1982 a 1998); e a terceira, de gradativa cooperação (2000 a 2010) ${ }^{7}$ (HE, 2019; MATSUDA, 2016;FANG; LI; SUN, 2018). Propomos ainda uma quarta fase, marcada por um engajamento ativo, de 2010 até o presente.

Com sua acessão à organização, a RPC ganhou também o direito de ocupar o assento permanente no CS, anteriormente destinado à República da China. A posição privilegiada entre os $\mathrm{P}-5$ atribuiu ao país uma responsabilidade diferenciada na elaboração e na implementação das operações de paz. Contudo, Pequim ainda não estava pronta para assumir tal responsabilidade, já que tinha discordâncias essenciais sobre o uso de tal in strumento na manutenção da paz e segurança internacional. Os chineses suspeitavam que as missões fossem usadas para promover a interferência internacional, em especial do ocidente, em assuntos domésticos dos Estados. Como forma de manter seu posicionamento sobre a defesa da soberania, mas evitando um comportamento condenatório no CS, a China optou por se abster de qualquer votação que envolvesse mandatos de operações de paznos anos $1970 .{ }^{8} \mathrm{O}$ distanciamento também se refletia na opção por não pagar suas contribuições ao orçamento das operações.

A primeira mudança na postura chinesa ocorreu em dezembro de 1981, na votação da Resolução 495 (1981) referente à operação das Nações Unidas no Chipre (no inglês, UNFICYP). Na reunião de adoção do documento, a delegação chinesa votou a favor da extensão do mandato e justificou sua posição pela mudança no contexto internacional e a evolução do instrumento das operações de paz. Desde que respeitasse a soberania e a independência dos Estados, e seguisse na íntegra os princípios da Carta da ONU, as missões não só seriam vistas pelo país comoinstrumentos válidos de manutenção da paz e segurança, como passariam a ter seu apoio (UNITED NATIONS SECURITY COUNCIL, 1981). Vale notar que essa primeira mudança reflete a transformação interna no mesmo período: enquanto de 1971 a 1976 o comportamento da RPC espelhou o radicalismo de sua política nacional, de 1980 em diante seu posicionamento foi influenciado pela necessidade de maior participação no sistema internacional motivada pelas reformasiniciadas em 1978.

O voto na Resolução 495 (1981) deu início, assim, à segunda fase da participação da RPC nas operações de paz, marcada pela gradativa aproximação e pela flexibilização de alguns princípios em prol da maior cooperação com o CS. Em 1982, como símbolo do novo compromisso chinês, Pequim pagou sua contribuição para o orçamento das operações pela primeira vez desde sua entradana ONU. Outras iniciativas de flexibilização marcaram os anos 1980:em 1988, o país aderiu ao Comitê Especial para Operações de Paz da ONU, cujo objetivo é revisar a prática das operações e elaborar recomendações para o aperfeiçoamento do instrumento. Já em 1989, ocorreu o primeiro envio de observadores civis chineses para o Grupo das Nações Unidas de Assistência a Transição (no inglês, UNTAG), cujo mandato envolveu a supervisão do processo de independência da Namíbia e da realização de eleições (ZHANG, 2014).

A participação com o envio de observadores, no início civis e depois militares, seria a característica central dessa segunda fase. Em abril de 1990, a RPC enviou observadores militares para a Organização das Nações Unidas para Supervisão da Trégua (UNTSO, na sigla em inglês) e repetiu a iniciativa em 1991, para a Missão de Observação Iraque Kuwait e para a Missão da ONU para o Referendo do Saara Ocidental (UNIKOM e MINURSO, respectivamente, nas siglas

\footnotetext{
$\mathrm{Na}$ literatura, diferentes autores optam por uma segmentação distinta entre as fases, mas é consenso que a transformação do posicionamento chinês partiu de uma postura crítica às missões para uma postura de cooperação e apoio ao instrumento do CS (HE, 2019; MATSUDA, 2016; FANG; LI; SUN, 2018).

${ }^{8}$ Segundo Matsuda (2016), a China se absteve nas votações envolvendo as três operações criadas pelo Conselho nos anos 1970.
} 
em inglês). Se, por um lado, a China se mostrou disposta a se aproximar da prática das operações e flexibilizar sua postura de abstenção para honrar o compromisso assumido em 1981, por outro, ainda havia clara resistência a um envolvimento mais amplo pelo receio de que os princípios básicos de respeito à soberania e não-interferência em assuntos internos pudessem ser violados na implementação dos mandatos. Por exemplo, em 1992, o país fez sua primeira contribuição com tropas para uma operação, a Autoridade de Transição da ONU no Camboja (UNTAC, na sigla em inglês), mas no discurso público ao CS, o representante chinês esclareceu que:

A ONU tem o dever de manter a paz e pode despachar forças de manutenção da paz, mas essas tropas não podem interferir nos assuntos internos do Estado [receptor]. A ONU não deve se tornar uma organização supranacional que intervém em diversos lugares ao redor do mundo.... China parti cipará das Operações de Paz da ONU, mas não se unirá a forças de manutenção da paz com tais objetivos. Essa é a política chinesa (QIAN apud MATSUDA, 2016, p. 52, tradução nossa). ${ }^{9}$

Para a UNTAC, a contribuição da China foi com tropas de apoio logístico e não combatentes, na tentativa de manter-se distante de questões próximas aos assuntos nacionais (HE, 2019; MATSUDA, 2016).

Em outubro de 1999, a China votou a favor da Resolução 1272 (1999) que determinava o estabelecimento da Administração para Transição da ONU no Timor Leste (UNTAET, na sigla em inglês), sob o capítuloVII da Carta da ONU. Apesar da UNTAET ter um mandatovoltado para a garantia de condições para um processo pacífico de transição no Timor Leste, a menção ao capítulo VII trazia a possibilidade de medidas coercitivas durante a implementação. Sendo assim, o voto positivo chinês no CS indicava uma flexibilização ainda maior quando comparado ao posicionamento mais restritivo do país no início dos anos 1970 (HE, 2007).

Já a fase que se inicia em 2000 foi marcada pela maior cooperação da China em relação às operações de paz. $\mathrm{O}$ período coincide também com a ampliação da participação chinesa em outras estruturas de governançaglobal, tanto pela entrada em novas instituições, como a Organização Mundial do Comércio (OMC), quanto por uma participação mais proativa nas instituições das quais já fazia parte (SHAMBAUGH, 2013). Segundo He (2019), o maior engajamento chinês era reflexo do novo conceito de "ascensão/desenvolvimento pacífico" ${ }^{10}$ que nortearia a política externa da RPC no novo milênio. Por isso, a China passou a prezar pela adequação às regras das instituições internacionais e se mostrou disposta a compartilhar os esforços referentes às operações de paz da ONU.

Em janeiro de 2000, pela primeira vez, a China contribuiu com um componente policial para uma missão: a UNTAET. O envio de policiais era um passo a mais, mas ainda mantinha o posicionamento de clara restrição a participação em atividades que pudessem assumir um viés coercitivo. Em março de 2003, a RPC enviou tropas logísticas (ou seja, nãocombatentes) para uma operação de paz, a Missão da Organização das Nações Unidas na República Democrática do Congo (MONUC, na sigla em inglês). Apesar de já ter enviado tropas logísticas para a UNTAC, em 1992, o envio para a MONUC foi visto de forma diferente: enquanto no Camboja esperava -se o maior envolvimento chinês por conta da proximidade geográfica, na República Democrática do Congo a iniciativa foi considerada como símbolo da maior cooperação internacional chinesa com operações de paz.

É também nessafase que a China demonstra seu compromisso com a qualidade dos contingentes enviados para as missões, tanto policiais quanto militares. Em agosto de 2000, a RPC inaugurou o China Peacekeeping CivPol Training Center, cujo objetivo é oferecer treinamento para unidades policiais que serão desdobradas pela ONU em operações de paz. $\mathrm{O}$ interessante é que o centro não se restringe ao treinamento dos policiais chineses, já tendo recebido delegações estrangeiras, inclusive de outros membros permanentes como Estados Unidos e Reino Unido (MINISTRY OF PUBLIC SECURITY, 2006).Já em 2009, foi criado o Centro de Peacekeeping do Ministério de Defesa Nacional da China, voltado ao

\footnotetext{
${ }^{9}$ Do original em inglês: “The UN has a duty to maintain peace, and may dispatch peacekeeping forces, but these troops must not interfere in a state's internal affairs. The UN must not become a supranational organization that starts to intervene in various places around the world...China is participating in UNPKO, but will not join any such peacekeeping forces. This is China's policy".

${ }^{10} \mathrm{O}$ termo é usado pela primeira vez pelo governo chinês, em 2003, como "ascensão pacífica”, mas foi substituído em 2004 por "de senvolvimento pacífico".
} 
treinamento de militares, em especial observadores e logísticos, chineses e estrangeiros. Ambas as iniciativas demonstram o renovado compromisso chinês com as atividades de manutenção da paz implementadas pela ONU (HE, 2019).

Por fim, a quarta fase - que se inicia em 2010 e é o objeto principal dessa análise -é marcada pelo engajamento ativo e mais assertivo da China nas diversas atividades relativas às operações de paz: inclusive, registrando os primeiros envios de tropas chinesas de combate para as missões de paz. Em 2013, a China decidiu fazer tal contribuição para a Missão Multidimensional das Nações Unidas de Estabilização Integrada (MINUSMA, na sigla em inglês), no Mali. Dois anos depois, em 2015, Pequim enviou um batalhão de infantaria para a Missão da ONU no Sudão do Sul (UNMISS, na sigla em inglês), que opera sob o capítuloVII e tem o mandato de proteção de civis (HE, 2019).

O aporte da China, como país contribuinte de tropas e de polícia, para as operações em geral também teve crescimento relevante nessa quarta fase, garantindo o lugar do país entre os 15 maiores contribuintes de 2010 a 2020 . É interessante notar que, em 2015, a RPC atingiu seu máximo patamar nas contribuições de pessoal, chegando a enviar um total de 3.045 chineses para as missões da ONU. Ao analisarmos os destinos de tais desdobramentos, é possível perceber que a China não só está presente nas missões com maior nível de periculosidade, como no Mali, Darfur e no Sudão do Sul, como também demonstra engajamento em missões diversificadas geograficamente (FANG; LI; SUN, 2018).

Em 2014, olivro branco de defesa do Exército de Libertação do Povo (ELP) elencou diversas áreas que receberiam maior atenção do governo chinês. Entre elas estavam as operações de paz da ONU. Um dos trechos do documento destacou que, com o fortalecimento e aperfeiçoamento doELP, seria intensificada também sua participação em operações de paz e missões humanitárias. As forças armadas chinesas se dedicariam a “(...) assumir maiores obrigações e responsabilidades internacionais, fornecendo bens públicos de segurança e contribuindo mais para a paz mundial e o desenvolvimento comum” (YAO, 2016, traduçãonossa). ${ }^{11}$

É a partir da intensificação do discurso de que a RPC se mostrou pronta para compartilhar a responsabilidade pelos "bens públicos de segurança” que se inicia a quarta fase do posicionamento chinês como engajamento ativo. Um marco importante nesse sentido foi o já mencionado discurso do presidente chinês, Xijinping, na ocasião da abertura da 70 a sessão da AG, em 2015. Como resultado, em 2016, foi criado o United Nations Peace and Development Trust Fund (UNPDF), que é composto por dois sub-fundos: um destinado ao pilar da paz e segurança e outrovoltado ao pilar do desenvolvimento sustentável.

O primeiro, relevante a esse estudo, é administrado em conjunto com o escritório do Secretário-Geral da ONU e tem como prioridade a capacitação de tropas e polícia dos países contribuintes. Até agora, já foram financiados 52 projetos, grande parte referente à melhoria da capacidade de participação dos países africanos em operações de paz. O interessante é que, apesar do fundo não ser diretamente destinado à tais operações, a maior parte dos projetos acaba sendo direta, ou indiretamente, voltada para elas (UNITED NATIONS, 2020c). ${ }^{12}$

O compromisso chinês com o financiamento de atividades de manutenção da paz se reflete ainda no incremento de sua contribuição ao orçamento das operações. Entre 2010 e 2020, a contribuição chinesa cresceu cerca de 285\%, elevando a China ao patamar de segundo maior contribuinte das operações, atrás apenas dos Estados Unidos, como vemos no Gráfico1.

\footnotetext{
${ }^{11}$ Do original: (...) and do their utmost to shoulder more international responsibilities and obligations, provide more public security goods, and contribute more to world peace and common development.

${ }^{12}$ Uma lista completa dos projetos do sub-fundo de paz e segurança pode ser acessada no website oficial do United Nations Peace and Development Trust Fund.
} 
Gráfico 1 - Participação dos P-5 no orçamento das Operações de Paz da ONU, de 2010 a 2020 (em porcentagem).

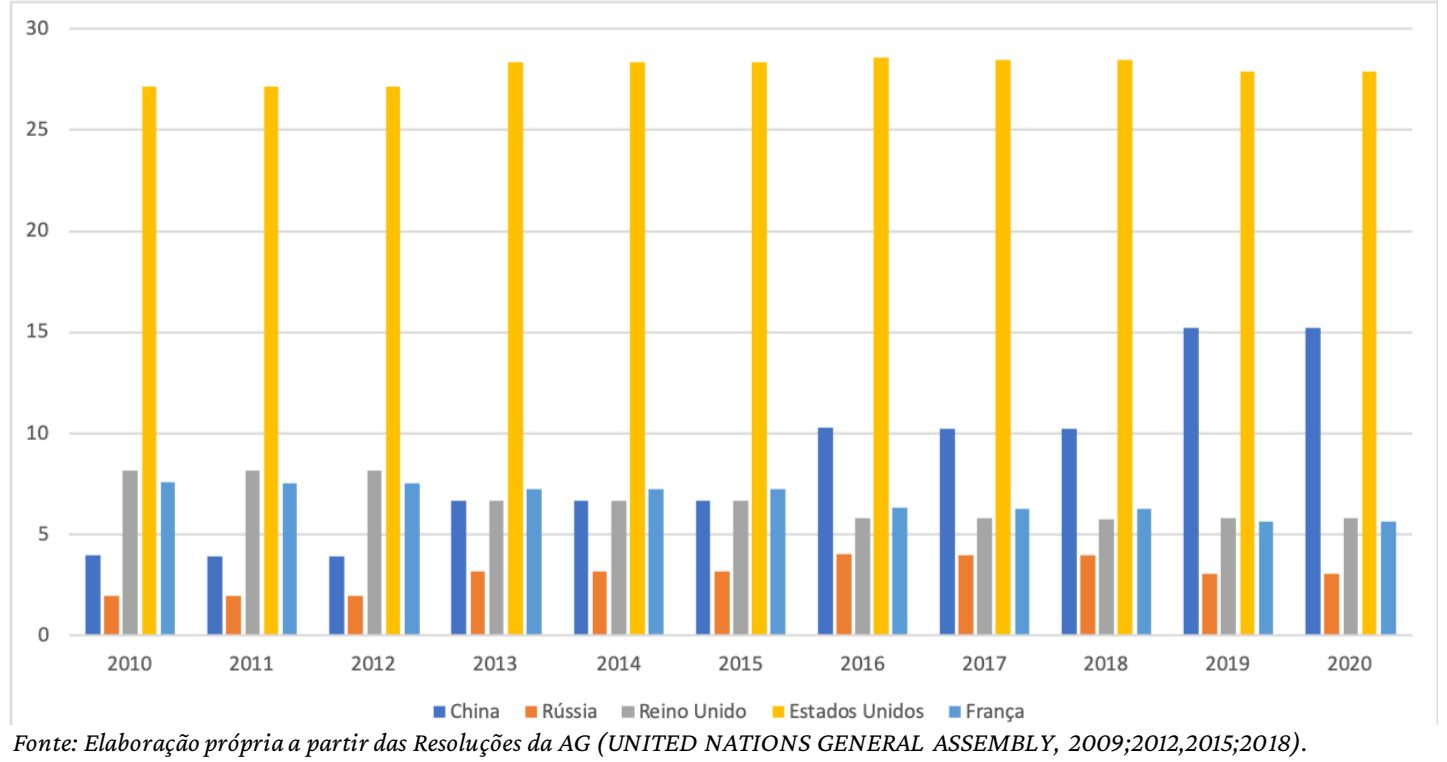

Seguindo a promessa de Xina abertura da AG, após 2015 a China passou a arcar com maiores responsabilidades e, com isso, maiores custos na implementação das operações de paz. A ampliação mais significativa ocorreu entre 2019 e 2020, quando a contribuição chinesa passou de 10,15\% do orçamento das operações para 15,21\% (UNITED NATIONS GENERAL ASSEMBLY, 2020a).

A quarta fase da participação chinesa nas operações de manutenção da paz fecha, assim, a transformação da postura da RPC sobre o tema. É possível observar que, quando comparada à postura dos anos 1970 - marcada pela abstenção e pelo distanciamento -, a China gradativamente passa a ser mais proativa na determinação dos mandatos, na organização de programas de capacitação e no financiamento das operações de paz. Diante desse contexto, quais as implicações positivas e negativas que a maior participação chinesa pode trazer a tal instrumento de manutenção da paze segurança internacionais?

\section{O engajamento chinês para as operações de paz: uma resposta aos desafios a partir do Sul Global?}

Frente às transformações do posicionamento da China para as operações de paz, cabe agora analisarmos como esse engajamento mais ativo responde aos principais desafios atualmente enfrentados pelo CS para a viabilização das missões. Em primeiro lugar, o que mais chama a atenção é que a participação chinesa reúne uma característica única no processo das operações de paz: a partir de 2016, a RPC passou a ser o segundo maior contribuinte do orçamento das missões e um importante contribuinte de tropas. O duplo papel pode contribuir para amenizar um dos principais gargalos atuais das operações de paz, decorrente da “divisão do trabalho” entre países desenvolvidos e países em desenvolvimento. Além disso, sendo, ao mesmo tempo, um membro permanente do CS e um grande TCC, a China assume um a posiçãofavorável na formulação e implementação das operações de paz, já que pode influenciar os mandatos e ainda se colocar como representante dos países em desenvolvimento nas etapas iniciais desse processo. Como vimos, tal diferencial responde a uma das maiores críticas do Sul Global ao déficit de representatividade na formulação dos mandatos das missões.

Esse perfil híbrido também pode garantir à China maior poder de barganha para cobrar o engajamento dos demais P-5. Se compararmos as contribuições de pessoal dos membros permanentes, entre 2010 e 2020 , fica clara a participação diferenciada por parte da RPC (Gráfico 2). Em 2020, por exemplo, as contribuições de tropas e polícia estavam distribuídas da seguinte forma entre os membros permanentes: China (2.443), França (659), Reino Unido (511), Rússia (23) e Estados Unidos (02) (DEPARTMENT OF PEACE OPERATIONS, 2020). 
Gráfico 2 - Contribuições de Tropas e Polícia para as Operações de Paz da ONU pelos P-5, 2010, 2015 e 2020.

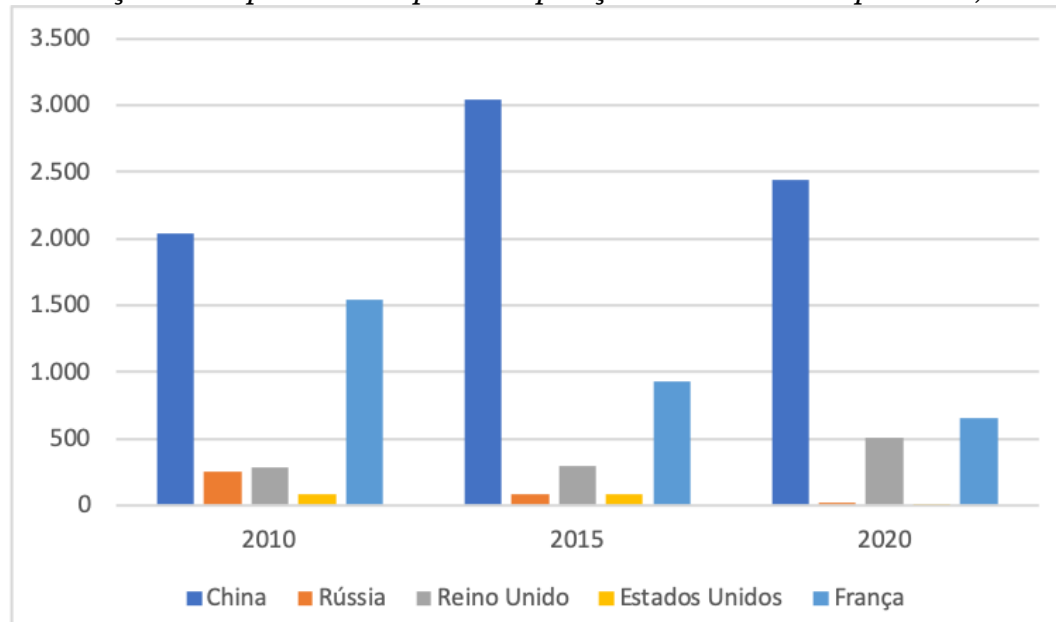

Fonte: Elaboração própria a partir dos dados Departamento de Operações de Paz (DEPARTMENT OF PEACE OPERATIONS, 2010;2015;2020).

Na medida em que a RPC assume novos compromissos, em especial a partir de 2015, o desequilíbrio entre os demais membros permanentes fica ainda maior. A considerável diferença nas contribuições tem consequência para o campo. Os países desenvolvidos e, em boa medida os P-5, têm uma capacidade militar superior àquela dos países em desenvolvimento. Suas tropas costumam ser mais bem equipadas e mais bem treinadas, como reflexo dos próprios investimentos individuais em segurança e defesa. Caso a emergência da China venha a constranger, no longo prazo, os demais membros permanentes a ampliarem sua contribuição de tropas, já teríamos uma consequência dessa nova correlação de forças, incentivando tropas mais bem treinadas e equipadas.

Outra implicação do engajamento ativo da China nas operações de paz está atrelada ao financiamento das atividades, o que também constitui um dos desafios anteriormente apontados para a viabilização das missões. Como indicado anteriormente, o orçamento da ONU para operações de paz, apesar da pequena redução, ainda representa um custo elevado para o financiamento de 12 missões. ${ }^{13}$ Um fator agravante desse desafio foi o anúncio, em 2018, por parte dos Estados Unidos de que limitariam sua contribuição para o orçamento das operações a $25 \%$. Historicamente, os Estados Unidos são os maiores contribuintes para o orçamento das operações de paz. Atualmente, a contribuição corresponde a 27,89\% do total do orçamento (UNITED NATIONS, 2020a).

Como mostra o Gráfico 1, a China passou a ser a segunda maior contribuinte do orçamento das missões em 2016, respondendo, hoje, por 15,21\% do total, ficando atrás apenas dos Estados Unidos, que ainda apresenta contribuição muito superior. No entanto, a RPC mantém seu compromisso de arcar com maiores custos das atividades de manutenção da paz, um fator interessante quando contrastado ao anúncio do governo dos Estados Unidos, sob a presidência de Trump, de reduzir sua contribuição para um máximo de 22\% (UNITED NATIONS 2020a). Como reflexo disso, o governo chinês vem adotando uma postura mais proativa nas discussões orçamentárias e, em seus discursos oficiais, não só tem cobrado o pagamento em dia, como tem pressionado os demais membros permanentes a evitar os dois problemas indicados acima:

(...) o principal problema relacionado ao financiamento das Nações Unidas é o fluxo de caixa insuficiente, que é causado primordialmente pela incapacidade de alguns Estados Membros em arcar com suas dívidas e contribuições integrais e dentro do prazo. (...) Os países com capacidade de pagamento, em particular, devem acertar suas dívidas rapidamente e traduzir sua promessa d e oferecer

\footnotetext{
${ }^{13}$ As operações financiadas pelo orçamento das operações de paz são: MINURSO (Saara Ocidental), MINUSCA (República Centro Africana), MINUSMA (Mali), MONUSCO (República Democrática do Congo), UNAMID (Darfur), UNDOF, UNFICYP (Chipre), UNIFIL (Líbano), UNISFA (Abyei), UNMIK (Kosovo), UNMISS (Sudão do Sul) e UNSOS (Escritório de apoio na Somália). Esse orçamento ainda ajuda nos custos da AMISOM (Somália) e o no financiamento das unidades de apoio tecnológico e operacional em Brindisi, Valencia e Entebbe (UNITED NATIONS, 2020b).
} 
suporte à causa e à reforma das Nações Unidas em ação (PEOPLE’S REPUBLIC OF CHINA MISSION TO THE UNITED NATIONS, 2019, p. 2, tradução nossa). ${ }^{14}$

O que chama atenção, contudo, é que a China, além de ampliar sua contribuição ao orçamento, também assumiu o compromisso de ofertar uma quantia significativa de fundos por meio do UNPDF, mencionado anteriormente. Até o momento, o Fundo já investiu aproximadamente US\$33 milhões em projetos do pilar de paz e segurança.É aqui que a segunda implicação da participação chinesa fica mais clara:entre as prioridades para o financiamento estão a construção de capacidades dos TCCs e PCCs, o fortalecimento da estrutura de paz e segurança na África e a melhoria da cooperação com organismos regionais. Tudo isso a partir dos princípios da cooperação sul -sul, que valoriza a horizontalidade, a troca de experiências e obenefício mútuo (UNITED NATIONS, 2020e).

Desse modo, se pela ampliada contribuição ao orçamento a RPC ganha a possibilidade de pressionar os demais membros permanentes por maior disciplina orçamentária, exigindo a adequação do orçamento ao mandato das missões, pela contribuição extra-orçamentária (com ênfase no UNPDF), a China pode imprimir nos programas de treinamento e cooperação das missões elementos da cooperação sul-sul. No longo prazo, ambas as estratégias podem acabar influenciando a dinâmica e a forma de conduta das operações de paz.

Por fim, a terceira implicação da maior participação chinesa, que recebe também a maior atenção da bibliografia, é a possibilidade de influenciar a estrutura normativa e de valores que sustenta essas operações até hoje. Desde sua concepção, as operações de paz da ONU foram marcadas pela influência ocidental, servindoem grande medida como veículos de valores e princípios típicos dessa parte do globo. A paz liberal, cujos dois pilares são instituições democráticas e economia de mercado, é, ainda hoje, o modelo propagado pelas missões nos processos de reconstrução pós-conflito (HE, 2019). A China, por sua vez, já demonstrou ser capaz de trilhar um caminho alternativo rumo ao desenvolvimento. Consequentemente, a identificação de sua maior participação nas operações vem frequentemente acompanhada de especulações sobre sua capacidade de desafiar as regras vigentes.

No entanto, em que pese o fato de que a RPC não deixa de expressar suas discordâncias sobre alguns temas relacionados às operações, pouco tem sido feito para interferir, ou até mesmo alterar, de forma significativa na dinâmica de tal instrumento. Nos discursos oficiais, são elementos comuns: a valorização da soberania como princípio norteador de qualquer ação do CS, o respeito à independência e à integridade territorial do Estado objeto da missão, a não-interferência, a priorização da construção de capacidade e a inclusão de agentes nacionais nos processos de paz. Quando tais preceitos são desafiados na elaboração ou renovação dos mandatos, a RPC costuma expressar sua insatisfação com a abstenção e não com o veto, o que lhe permite marcar sua posição, mas sem inviabil izar o processo (HE, 2019; SHAMBAUGH, 2013).

Mesmo quando o debate se desenvolve em torno do uso da força e do guarda -chuva do capítulo VII da Carta da ONU, a China não deixa de participar. Sua posição sobre esse tema é bem difundida: o uso da força não d eve ser feito se puder interferir em assuntos internos, e, se tiver que ser feito, só deve ser colocado em prática mediante a autorização das partes. Nesse quesito, o reforço dos três princípios das operações de paz é a estratégia usada para a China para construir seus posicionamentos. O resultado é uma postura mais flexível: quando o uso da força é para auto-defesa ou defesa do mandato, a RPC não se indispõe a cooperar (HE, 2019).

Nas operações em que o modelo da paz liberal é mais marcado, a participação chinesa também não deixa de ocorrer. Ela apenas se concentra em atividades que não passam pelas reformas institucionais e que são geralmenteligadas à logística e infraestrutura (FANG; LI; SUN, 2018). Apesar de ser crítica de tal abordagem, a RPC ainda não conseguiu estabelecer uma versão alternativa que possa ser aplicada às operações de paz. Autores como Fang, Li e Sun (2018) sugerem que a China poderia considerar uma ideia de "paz desenvolvimentista”, cujo fundamento seriam instituições fortes, estabilidade e desenvolvimento econômico com bases nacionais. Entretanto, na realidade, a transformação da posição

\footnotetext{
${ }^{14}$ Do original em inglês: (...) the main problem facing the finance of the UN is insufficient cash flow, which is primarily caused by the failure of some Member States to pay their dues and assessments in full and on time. (...) Those countries with the capacity to pay, in particular, should expeditiously settle their dues and translate their promise to support the cause and reform of the UN into action.
} 
chinesa é recente e, portanto, ainda lhe falta a capacidade de influenciar a agenda, as ideias e os processos que sustentam as operações e paz. O país ainda ocupa poucos papeis de liderança na estrutura das missões e seus representantes e especialistas não tem o suficiente poder de barganha para promover grandes alterações nas normas.

\section{Conclusão}

Nos 50 anos desde a sua entrada na ONU, a RPC passou por uma transição em seu posicionamento no CS, no que diz respeito às operações de paz.Para entender esse processo, partimos da análise desse instrumento, apontando o seu objetivo e os principais desafios enfrentados nos dias atuais. A transição da atuação chinesa em relação às operações se reflete nas quatro fases analisadas neste artigo: uma fase de abstenção, entre 1971 e 1981; de aproximação e flexibilização, de 1982 a 1998; de gradativa cooperação, entre 2000 e 2010; e de engajamento ativo, de 2010 até 202 0, como proposto pelas autoras. Com isso, observamos a emergência da China como ator relevante no processo de elaboração, financiamento e implementação das operações de paz da ONU.

Analisando os documentos oficiais da organização, percebemos que esse destaque chinês, nessa fase que chamamos de engajamento ativo, vai ao encontro dos principais desafios enfrentados pelo Conselho no emprego das operações de paz: financiamento e contribuição de contingentes militares.

Ainda que esse cenário promova algumas mudanças ou ajustes entre os principais atores dessa dinâmica, não está clara a disposição, ou capacidade, chinesa de promover alterações mais significativas na estrutura normativa ou mesmo no processo de formulação das operações de paz. As implicações mais visíveis até o momento dizem respeito ao maior envolvimento da China nos processos de negociação e ao fornecimento de recursos para áreas negligenciadas, como o treinamento e a construção de capacidades.

\section{Referências}

DEPARTMENT OF PEACE OPERATIONS (DPO). Contributors to UN Peacekeeping Operations by Country and Post Police, UN Military Experts on Mission, Staff Officers and Troops, 31 de dezembro de 2020. Disponível em: https://peacekeeping.un.org/sites/default/files/01_summary_of_contributions_33.pdf. Acesso em 04 mar. 2020.

DEPARTMENT OF PEACE OPERATIONS (DPO). Ranking of Military and Police Contributions to UN Operations, 30 de dezembro de 2010. Disponível: https://peacekeeping.un.org/sites/default/files/dec10_2.pdf. Acesso em: 15.jul.2021.

DEPARTMENT OF PEACE OPERATIONS (DPO). Ranking of Military and Police Contributions to UN Operations, 31 de dezembro de 2015. Disponível em: https://peacekeeping.un.org/sites/default/files/dec15_2.pdf. Acesso em: 28 jun. 2018.

DIGOLIN, Kimberly Alves. Cooperação em operações de paz: atuações e iniciativas conjuntas entre Argentina, Brasil e Chile. Dissertação de mestrado. Programa de Pós-graduação em Relações Internacionais San Tiago Dantas, Universidade Estadual Paulista, Universidade Estadual de Campinas e Pontifícia Universidade Católica de São Paulo, Brasil, 2018, 130 p.

FAGANELLO, Priscila. Operações de Manutenção da Paz da ONU. Brasília: FUNAG, 2013.

FANG, Songying; LI, Xiaojun; SUN, Fanglu. China's Evolving Motivations and Goals in UN Peacekeeping Participation. International Journal, v. 73, n.3, p. 464-473, 2018.

HE, Yin. China's Changing Policy on UN Peacekeeping Operations. Estocolmo: Institute for Security and Development Policy, 2007.

HE, Yin. China Rising and Its Changing Policy on UN Peacekeeping. In: CONING, Cedric; PETER, Mateja. (Eds). Peace Operations in a Changing Global Order. Nova Iorque: United Nations, 2019, cap. 13, p. 253-276.

MALONE, David; THAKUR, Ramesh. Racism in Peacekeeping. Globe and Mail. Toronto, Publicado em 30 outubro 2000. Atualizado em 7 abril 2018. Disponível em: https://www.theglobeandmail.com/opinion/racism-in-peacekeeping/article1340656/. Acesso em: 29 jun. 2019.

MATSUDA, Yasushiro. China's UN Peacekeeping Operations Policy: analysis of the factors behind the police shift toward active engagement. International Circumstances in the Asia-Pacific Series (China), março de 2016. Disponível em: www2.jiia.or.jp/en/pdf/digital_library/china/160331_Yasuhiro_Matsuda.pdf. Acesso em: 30 jun. 2019. 
PEOPLE'S REPUBLIC OF CHINA MISSION TO THE UNITED NATIONS. Statement by the Permanent Mission of China to the United Nations at the Second Resumed Session of the Fifth Committee of the General Assembly on Agenda Item 138: Improving the Financial Situation of the United Nations, 16 de maio de 2019. Disponível em: https://www.un.org/en/ga/fifth/73/statements/138.\%20Financial\%20Situation/C5_73_2r_ST_2019_05_16_Item_138_Financial\%20Sit uation_China.pdf. Acesso em: 26 jan. 2020.

SHAMBAUGH, David. China goes global: the partial power. Nova Iorque: Oxford University Press, 2013.

UNITED NATIONS (UN). Approved resources for peacekeeping operations for the period from $01 \mathrm{July} 2020$ to $31 \mathrm{June} 2021,24$ de junho de 2020 a, A/C.5/74/18. Disponível em: https://documents-ddsny.un.org/doc/UNDOC/GEN/N20/158/14/PDF/N2015814.pdf?OpenElement. Acesso em: 20 jan. 2020.

UNITED NATIONS (UN). Charter of the United Nations. New York: United Nations Publications, 2015.

UNITED NATIONS (UN). How we are funded. In: United Nations Peacekeeping, 2020 b. Disponível em: https://peacekeeping.un.org/en/how-we-are-funded. Acesso em:20 jan. 2020.

UNITED NATIONS (UN). List of Projects. In: United Nations Peace and Development Trust Fund, 2020 c. Disponível em: https://www.un.org/en/unpdf/peace.shtml. Acesso em: 20 jan. 2020.

UNITED NATIONS (UN). Our history. In: United Nations Peacekeeping, 2020 d. Disponível em: https://peacekeeping.un.org/en/ourhistory. Acesso em: 20 jan. 2020

UNITED NATIONS (UN). Priorities. In: United Nations Peace and Development Trust Fund, 2020 f. Disponível em: https://www.un.org/en/unpdf/priorities.shtml. Acesso em: 20 jan.2020.

UNITED NATIONS (UN). Role of the General Assembly. In: United Nations Peacekeeping, 2020 g. Disponível em: https://peacekeeping.un.org/en/role-of-general-assembly. Acesso em 20 jan. 2020.

UNITED NATIONS (UN). Role of the Security Council. In: United Nations Peacekeeping, 2020 h. Disponível em: https://peacekeeping.un.org/en/role-of-security-council. Acesso em: 20 jan. 2020.

UNITED NATIONS GENERAL ASSEMBLY (UNGA). Implementation of General Assembly resolutions 55/235 and 55/236, 31 de dezembro de 2009,A/64/220/Add.1. Disponível em: https:/www.un.org/en/ga/search/view_doc.asp?symbol=A/64/220/Add.1. Acesso em: 15 jul.2021.

UNITED NATIONS GENERAL ASSEMBLY (UNGA). Implementation of General Assembly resolutions 55/235 and 55/236, 27 de dezembro de 2012, A/67/224/Add.1. Disponível em: https://www.un.org/en/ga/search/view_doc.asp?symbol=A/67/224/Add.1. Acesso em 15 jul.2021.

UNITED NATIONS GENERAL ASSEMBLY (UNGA). Implementation of General Assembly resolutions 55/235 and 55/236, 28 de dezembro de 2015 a, A/70/331/Add.1. Disponível em: https:/www.un.org/en/ga/search/view_doc.asp?symbol=A/70/331/Add.1. Acesso em: 28 jun. 2019.

UNITED NATIONS GENERAL ASSEMBLY (UNGA). Implementation of General Assembly resolutions 55/235 and 55/236, 24 de dezembro de 2018, A/73/350/Add.1. Disponível em: https://documents-ddsny.un.org/doc/UNDOC/GEN/N18/461/91/PDF/N1846191.pdf?OpenElement. Acesso em: 15 jul.2021.

UNITED NATIONS GENERAL ASSEMBLY (UNGA). Official Records $-\mathbf{1 3}^{\text {th }}$ plenary meeting, 28 de setembro de 2015 b, A/70/PV.13. Disponível em: https://undocs.org/en/A/70/PV.13. Acesso em: 30 jun. 2019.

UNITED NATIONS SECURITY COUNCIL (UNSC). Security Council Official Records $\mathbf{- 2 3 1 3 ^ { \text { th } }}$ meeting, 14 de dezembro de 1981. Disponível em: https://digitallibrary.un.org/record/551728/files/S_PV-2313-EN.pdf. Acesso em: 29 jun. 2019.

UZIEL, Eduardo. Conselho de Segurança, as operações de paz e a inserção do Brasil no mecanismo de segurança coletiva das Nações Unidas. Brasília: FUNAG, 2010.

WEISS, Thomas; KUELE, Giovanna. The Global South and UN Peace Operations. E-International Relations, 03 fevereiro. 2019.Disponível em: https://www.e-ir.info/2019/02/03/the-global-south-and-un-peace-operations/\#_ftn2. Acesso em: 28 jun. 2018.

YAO, Jianing. White Paper 2014. Ministry of National Defense of the People's Republic of China, 13 de julho de 2016. Disponível em: http://eng.mod.gov.cn/publications/2016-07/13/content_4768294.htm. Acesso em: 29 jun.2019.

\begin{tabular}{ll}
\hline Funções de colaboração exercidas & \\
\hline Talita de Mello Pinotti: & Metodologia; Visualização; Investigação; Escrita (primeira redação); Escrita (revisão eedição); \\
Patricia Capelini Borelli: & Visualização; Investigação; Escrita (primeira redação); Escrita (revisão e edição); \\
\hline
\end{tabular}

